\title{
Following through on Good Intentions: The Power of Planning Prompts
}

\section{Citation}

Milkman, Katherine L., John Beshears, James J. Choi, David Laibson, and Brigitte C. Madrian. 2012. Following through on Good Intentions: The Power of Planning Prompts. HKS Faculty Research Working Paper Series RWP12-024, John F. Kennedy School of Government, Harvard University.

\section{Published Version}

http://web.hks.harvard.edu/publications/workingpapers/citation.aspx?Publd=8410

\section{Permanent link}

http://nrs.harvard.edu/urn-3:HUL.InstRepos:8830778

\section{Terms of Use}

This article was downloaded from Harvard University's DASH repository, and is made available under the terms and conditions applicable to Other Posted Material, as set forth at http:// nrs.harvard.edu/urn-3:HUL.InstRepos:dash.current.terms-of-use\#LAA

\section{Share Your Story}

The Harvard community has made this article openly available.

Please share how this access benefits you. Submit a story.

\section{Accessibility}




\title{
Following through on Good Intentions: The Power of Planning Prompts Faculty Research Working Paper Series
}

\author{
Katherine L. Milkman
}

The Wharton School, University of Pennsylvania

John Beshears

Stanford Graduate School of Business and NBER

James J. Choi

Yale School of Management and NBER

\section{David Laibson}

Harvard University and NBER

Brigitte C. Madrian

Harvard Kennedy School and NBER

\section{May 2012 \\ RWP12-024}

\footnotetext{
The views expressed in the HKS Faculty Research Working Paper Series are those of the author(s) and do not necessarily reflect those of the John F. Kennedy School of Government or of Harvard University. Faculty Research Working Papers have not undergone formal review and approval. Such papers are included in this series to elicit feedback and to encourage debate on important public policy challenges. Copyright belongs to the author(s). Papers may be downloaded for personal use only.
} 


\title{
Following through on Good Intentions: The Power of Planning Prompts
}

\author{
Katherine L. Milkman \\ The Wharton School, University of Pennsylvania \\ John Beshears \\ Stanford Graduate School of Business and NBER \\ James J. Choi \\ Yale School of Management and NBER \\ David Laibson \\ Harvard University and NBER \\ Brigitte C. Madrian \\ Harvard Kennedy School and NBER
}

Last Revised: March 29, 2012

\begin{abstract}
We study whether prompts to form and recall a plan can increase individuals' responsiveness to reminders to make and attend beneficial appointments. At four companies, all employees due for a colonoscopy were randomly assigned to receive either a control mailing or a treatment mailing. The mailings were identical except that the control mailing included a blank sticky note while the treatment mailing included a sticky note that prompted the recipient to write down the appointment date for a colonoscopy and the name of the doctor who would conduct the procedure. During the seven-month follow-up period, $7.2 \%$ of treatment employees received a colonoscopy compared to $6.2 \%$ of control employees, a statistically significant difference that is roughly equal to the variation in compliance associated with a 10 percent increase in the fraction of the procedure's cost covered by insurance. The treatment effect was largest for demographic groups judged to be at the highest risk of failing to receive a colonoscopy due to forgetfulness.
\end{abstract}

Acknowledgments: We thank Prashant Srivastava, Jennifer Lindner, and our other contacts at Evive Health for conducting the field experiment and providing the data. Michael Puempel provided excellent research assistance. We acknowledge individual and collective financial support from the National Institute on Aging (grants P01AG005842 and P30AG034532). See the authors' websites for lists of their outside activities. 


\section{Introduction}

There are many beneficial behaviors that individuals intend to execute but fail to follow through on. Often these are behaviors that employers would like to encourage their employees to pursue, such as signing up for and attending educational programs offered at work, scheduling and attending meetings with mentors or mentees, and scheduling and attending medical appointments.

In this paper, we describe a field experiment testing the efficacy of a "nudge" (Thaler and Sunstein, 2008) designed to help people schedule and keep important appointments. The nudge was a sticky note with the text: "Don't forget! Colonoscopy appointment with: on:

" (see Figure 1). This sticky note was attached to a mailer urging recipients to undergo a colonoscopy.

We demonstrate that including this (nearly costless) planning prompt in a mailing increases the fraction of recipients undergoing a colonoscopy during the seven months following the mailing from $6.2 \%$ (in a control condition including a blank sticky note) to $7.2 \%$, a $16 \%$ increase in compliance. Colon cancer is the second-leading cause of cancer death in the United States, resulting in approximately 50,000 fatalities per year (U.S. Preventative Services Task Force, 2008). According to estimates from the U.S. Government's Preventative Services Task Force (2008), 18,800 lives could be saved each year if all those advised to seek colorectal screenings based on national guidelines complied, as colonoscopies dramatically reduce colon cancer mortalities (Zauber et al., 2012). Zauber et al. (2008) estimate that for every 1,000 additional individuals who follow the recommended schedule of colonoscopies (every 10 years for adults aged 50-75), approximately 250 life-years are gained. 
Although we examine the planning prompt's effect on subsequent colonoscopies, the intervention tested should be effective at helping individuals follow through on a wide range of other important behaviors that may not be implemented because of forgetfulness or procrastination.

Forgetfulness and procrastination frequently prevent individuals from engaging in beneficial behaviors (for a review of the literature on forgetfulness, see Schacter, 1999; for a review on procrastination, see O'Donoghue and Rabin, 1999). When forgetfulness prevents people from following through on their plans, it is typically attributable to one of two types of memory failures: (a) transience, the tendency to lose access to information as time passes, or (b) absent-mindedness, the tendency to engage in "inattentive or shallow processing that contributes to weak memories of ongoing events or forgetting to do things in the future" (Schacter, 1999). Procrastination harms follow-through when self-control failures cause people to put off behaviors they know they should engage in (e.g., studying, exercising, scheduling a medical appointment) and instead absorb themselves in more instantly gratifying activities (Milkman, Rogers, and Bazerman, 2008). This can lead to a vicious cycle where constructive actions that individuals intend to take are never completed.

The sticky note we study prompts people to form a plan or implementation intention of the form "when situation $x$ arises, I will implement response $y$ " (Gollwitzer, 1999; Gollwitzer and Sheeran, 2006) and display a visual reminder of this plan in their environment. There are several mechanisms through which the sequence of events initiated by the sticky note may increase goal attainment. One mechanism is cognitive: by associating a future cue (the date written on the sticky note) with a plan of action (attending the appointment), individuals who have formed implementation intentions are more likely to remember to follow through on their 
plan. A second mechanism is logistical: planning prompts encourage people to generate solutions to practical challenges that often thwart goal attainment. For example, prompted people will make an appointment in the first place, and they may also block off time on their calendar, arrange for necessary coverage at home or work while they will be unavailable, etc. A third mechanism is material: a sticky note containing a prompt to write down and remember a plan of action may be more likely to be retained in a decision maker's physical environment than a blank sticky note, thereby serving as a visual reminder and increasing the chances of plan followthrough.

Past research has demonstrated that implementation intentions increase the rate at which people follow through on their intentions across a wide range of simple behaviors, including voting (Nickerson and Rogers, 2010), picking up course materials (Dholakia and Bagozzi, 2003), and receiving a flu shot (Milkman et al., 2011). Past field research on the power of planning prompts has focused on increasing engagement in behaviors that (a) are relatively easy to undertake (e.g., receiving a flu shot, voting in elections), (b) require only a single step to complete, unlike scheduling and keeping an appointment, and (c) can be completed within a short period of time following the formation of a plan of action (i.e., within at most several weeks), when transience — the tendency to lose access to information as time passes - is unlikely to pose a major obstacle. This paper studies a more challenging test of the power of prompts to form and remember plans. We examine follow-through on a valuable behavior that many people dread: undergoing a colonoscopy. The outcome requires both making an appointment and attending it many weeks in the future. Our findings suggest that planning prompts can be used to increase execution of a wider range of important behaviors than previously demonstrated. 
Our study is also only the second in the planning prompts literature to avoid several important confounding explanations for its results. Milkman et al. (2011) is the first paper to demonstrate that planning prompts have powerful effects in the field in the absence of confounds such as social pressure, reporting bias, attrition, and demand effects. As noted in Milkman et al. (2011), previous field studies suffered from the following limitations:

- an inability to distinguish the pure effect of the planning intervention from the effect of social pressure because the intervention involved face-to-face or telephone contact (Leventhal, Singer, and Jones, 1965; Nickerson and Rogers, 2010; Leventhal, Watts, and Pagano, 1967; Orbell, Hodgkins, and Sheeran, 1997; Lawton, Conner, and Prestwich, 2003; Sheeran and Orbell, 1999)

- an inability to distinguish the effect of the planning treatment from the effect of providing additional relevant information along with the planning prompt (Leventhal, Singer,, and Jones, 1965; Leventhal, Watts and Pagano, 1967; Orbell, Hodgkins, and Sheeran, 1997; Rutter, Steadman, and Quine, 2006; Bamberg, 2002; Arrmitage and Conner, 2001)

- a reliance on self-reported data, which is vulnerable to reporting bias (Leventhal, Watts, and Pagano, 1967; Orbell, Hodgkins, and Sheeran, 1997; Lawton, Conner, and Prestwich, 2003; Sheeran and Orbell, 1999; Sniehotta, Scholz, and Schwarzer, 2006; Koestner et al. 2002; Verplanken and Feas, 1999; Arrmitage and Conner, 2001)

- a reliance on data involving subjects who knew they were part of an experiment, which might have produced demand effects (Bamberg, 2000; Koestner et al., 2002; Verplanken and Faes, 1999; Arrmitage and Conner, 2001)

- an inability to precisely measure the impact of the intervention due to a small sample size (Bamberg, 2000; Leventhal, Singer, and Jones, 1965; Leventhal, Watts and Pagano, 
1967; Orbell, Hodgkins, and Sheeran, 1997; Lawton, Conner, and Prestwich, 2003;

Sheeran and Orbell, 1999; Sniehotta, Scholz, and Schwarzer, 2006; Sheeran and Orbell, 2000)

- high rates of subject attrition (Orbell, Hodgkins, and Sheeran, 1997; Lawton, Conner, and Prestwich, 2003; Sheeran and Orbell, 1999; Sniehotta, Scholz, and Schwarzer, 2006; Sheeran and Orbell, 2000)

The current study does not suffer from any of these problems. We experienced negligible attrition, included over 10,000 people in our experiment who were not aware they were being observed, relied on insurance claims rather than self-reports to measure outcomes, provided identical information to subjects across conditions, and only contacted study participants by mail to implement our experiment. This research therefore provides new evidence that planning prompts can change behavior meaningfully, independent of the confounding factors described above.

The paper proceeds as follows: Section 2 describes the experimental design and procedures; Section 3 describes the results of the study; and Section 4 concludes.

\section{Experimental Design and Procedures}

\subsection{Study Participants}

The participants in this study were 11,918 employees of four different U.S. companies who resided in 49 different U.S. states. Participants were selected for inclusion because the Centers for Disease Control (CDC) criteria (U.S. Preventive Services Task Force, 2008) indicated that they were due for a colonoscopy, and they had received either one or zero previous mailings informing them of this fact. (For individuals who are not at an elevated risk of 
developing colorectal cancer, the CDC recommends regular screening for colorectal cancer beginning at age 50 and continuing every 10 years until age 75.) Participants at Employer \#1 were selected based on these criteria in June 2010; participants at Employer \#2 were selected based on these criteria in July 2010; and participants at Employers \#3 and \#4 were selected based on these criteria in August 2010. Males made up 50.8\% of the sample; $95.0 \%$ were Caucasian; the mean age was 57.5 years $(\mathrm{SD}=4.9$ years; $\min =45.1$ years, $\max =75.6$ years $)$; and $76.8 \%$ had not previously received a mailing indicating they should receive a colonoscopy (all others had previously received one mailing that had not successfully motivated them to receive a colonoscopy). Table 1 presents detailed summary statistics describing the population of study participants.

\subsection{Procedures}

All four employers whose employees participated in the study retained Evive Health, a personalized healthcare communications provider, to send mailings to their employees. These mailings informed employees that national guidelines recommended they receive a colonoscopy, provided the name and number of a doctor (their proctologist whenever he/she was known) who they could call to schedule an appointment, and informed them of the percentage of their colonoscopy bill that would be covered by their insurance $($ mean $=87.2 \%, \mathrm{SD}=8.9 \%, \min =$ $70.0 \%, \max =100.0 \%$ ). Mailings were sent to targeted employees in June (Employer \#1), July (Employer \#2), and August 2010 (Employers \#3 and \#4).

Evive Health developed two versions of this mailing containing identical information about how and why to obtain a colonoscopy. Both mailers included a headline stating, "A simple sticky note can really catch your eye," along with text describing how sticky notes can be used to 
help people remember to do important things (like getting a colonoscopy). Attached to the top of the control condition mailer was a blank yellow sticky note. In the treatment condition, in place of the blank yellow sticky note was a yellow sticky note containing a planning prompt. The sticky note urged: "Don’t forget! [line break] Colonoscopy appointment". Below these two lines of text were two lines prompting the employee to write down a detailed plan for receiving a colonoscopy. The first planning prompt line contained the word "with" followed by blank line where the recipient could write his or her doctor's name. The second planning prompt line contained the word "on" followed by a blank line where the recipient could write the date of his or her appointment. Not only do these planning prompts encourage the formation of a plan, but they may have also made it more likely that the recipient used the sticky note as a physical reminder of his or her appointment. Figure 2 illustrates the appearance of the control and treatment condition mailers, which were sent on $81 / 2$ "x 11 " sheets of paper.

Participants were randomly assigned to one of the two experimental conditions using a random number generator. The primary outcome of interest is the receipt of a colonoscopy on or before the end of February 2011 (approximately 6-8 months after the mailings were sent) as measured by insurance claims data for all employees in our sample.

\section{Results}

\subsection{Success of Random Assignment}

A total of 5,898 participants were assigned to the control condition, and a total of 6,020 participants were assigned to the treatment condition. Evive's random assignment algorithm achieved experimental balance: There are no observable differences significant at the $5 \%$ level between participants assigned to the control and treatment groups, and there is just one 
marginally significant difference across conditions (in the assignment of participants from Employer \#1 to conditions) (see Table 1).

\subsection{Do Planning Prompts Significantly Change Behavior?}

Figure 3 shows that $6.2 \%$ of employees in the control condition received a colonoscopy between the time the mailing was sent and the end of February 2011, while $7.2 \%$ in the treatment condition received a colonoscopy during the same time period. These percentages differ significantly from one another $(z(11,916)=-2.08, p=0.037)$. We also observe the speed with which an individual received a colonoscopy following the mailing of his or her letter $(\min =30$

days, $\max =255$ days). The $5^{\text {th }}$ percentile of the wait time distribution in the control condition is 178 days, while in the treatment condition it is 155 days.

We conduct both an ordinary least squares regression analysis to estimate the impact of the treatment mailing on the probability of colonoscopy take-up and a Cox proportional hazards regression analysis to estimate the impact of the treatment mailing on the speed of colonoscopy receipt, controlling for all observable characteristics of the mailing recipient. Because a marginally greater fraction of the treatment group is drawn from Employer \#1, we include employer fixed effects in these regressions.

Model 1 in Table 2 corroborates the differences in means discussed above-even after controlling for covariates, the treatment mailers lead to a statistically significant 1 percentage point higher rate of colonoscopy receipt than the control mailers. This is roughly equal to how much colonoscopy rates increase as we move from one group of employees in our sample to 
another group whose insurance covers 10 percentage points more of the colonoscopy's cost. ${ }^{1}$ The only other factor that matters in explaining colonoscopy receipt is being Caucasian which is associated with a 2.3 percentage point higher rate of colonoscopy receipt relative to ethnic minorities.

Model 2 in Table 2 demonstrates that treatment mailers lead study participants to receive colonoscopies with a significantly higher daily hazard rate. The hazard ratios in Table 2, Model 2 indicate that being in the treatment condition increases the daily hazard of receiving a colonoscopy by a factor of 1.16 , on average, for all employees. As in Model 1, this is similar in magnitude to the impact of moving from one group of employees in our sample to another group whose insurance covers 10 percentage points more of the colonoscopy's cost. The daily hazard of receiving a colonoscopy is increased by a factor of 1.45 for Caucasians.

\subsection{Does the Planning Prompt Treatment Effect Vary with Proxies for Forgetfulness?}

If planning prompts increase take-up of desirable behaviors in part by reducing the likelihood that individuals forget to engage in those behaviors, then they should be more effective among populations that face greater struggles with forgetfulness. While we cannot directly measure forgetfulness in the population we study, we do know a number of things about our participants that may correlate with forgetfulness.

To assess which of the observable characteristics of our study population would be appropriate proxies for forgetfulness, we conducted an online survey. Fifty-four survey respondents were recruited online through Amazon's Mechanical Turk (an internet micro-

\footnotetext{
${ }^{1}$ Note that the variation in insurance costs is not necessarily exogenous, so a causal interpretation about the impact of cost is speculative.
} 
employment marketplace) and were paid $\$ 0.10$ each to complete what was described as a 2-3 minute survey where they would be asked to predict what types of people are the most forgetful. For each available predictor variable in our data set (gender, age, having one or more children, race, first reminder, and level of insurance coverage), we asked survey respondents to predict which types of people would be more likely to struggle with forgetfulness in the context of remembering a medical test. Responses were elicited on a 5-point scale (exact survey materials are presented in the Appendix). For example, when evaluating whether males or females are at higher risk of forgetting to receive a medical test, a respondent answered on a 5-point scale ranging from " $1=$ strongly agree that males are more forgetful," to " $5=$ strongly agree that females are more forgetful."

For all observable population characteristics except race, our survey respondents predicted that forgetfulness would vary significantly as a function of the characteristic in question. Specifically, survey respondents predicted that males are at higher risk of forgetting than females $\left(M_{\text {agree_male=1 }}=2.2, H_{0}: M_{\text {agree_male=1 }} \neq 3, t(53)=-7.1, p<0.001\right)$; older adults are at higher risk of forgetting than younger adults $\left(M_{\text {agree_older=1 }}=2.4, H_{0}: M_{\text {agree_older=1 }} \neq 3, t(53)=-3.1\right.$, $p<0.01$ ); adults with children are at higher risk of forgetting than adults without children $\left(M_{\text {agree_nochildren=1 }}=3.6, H_{0}: M_{\text {agree_nochildren=1 }} \neq 3, t(53)=3.5, p<0.001\right)$; those who did not comply with a previous reminder are at higher risk of forgetting than those with no such history $\left(M_{\text {agree_2ndReminder=1 }}=2.0, H_{0}: M_{\text {agree_2ndReminder=1 }} \neq 3, t(53)=-5.5, p<0.001\right)$; and adults with less insurance coverage are at higher risk of forgetting than adults with more insurance coverage $\left(M_{\text {agree_lessCoverage=1 }}=2.3, H_{0}: M_{\text {agree_lessCoverager=1 }} \neq 3, t(53)=-4.7, p<0.001\right)$. However, survey 
respondents predicted that Caucasians are at no significantly different risk of forgetting than $\operatorname{Hispanics}^{2}\left(M_{\text {agree_Caucasian=1 }}=3.2, H_{\mathrm{o}}: M_{\text {agree_Caucasian=1 }} \neq 3, t(53)=1.7, p=0.1\right)$.

Figure 4 shows the interactions between the treatment effect of our planning prompt and the characteristics that survey respondents indicated are significantly likely to relate to forgetfulness. The treatment effects illustrated in Figure 4 are based on our primary OLS regression specification (Table 2, Model 1) with one added interaction term-an interaction between the planning prompt dummy and the observable characteristic in question (e.g., age). While none of these interaction terms is a significant predictor of colonoscopy take-up on its own (likely due to power limitations imposed by the low compliance rates overall across our sample), every single interaction moves in the predicted direction: members of the group perceived to be at higher risk of forgetting show a stronger positive response to our planning prompt. To strengthen our power to examine individual treatment effect differences along the dimension of forgetfulness, we create a single forgetfulness proxy variable based on our survey data using the following formula:

$$
\text { forget_proxy }=\text { male }+ \text { child }+ \text { second_reminder }+ \text { normalized age }- \text { normalized coverage }
$$

where both continuous predictors (age and coverage) are divided by their total spread (maximum value minus minimum value) so that all variables summed to create the proxy have the same one-point range of possible values. When we include this forgetfulness proxy variable as well as the interaction between forget_proxy and our planning prompt treatment dummy in our primary regression specifications, we find a significant positive interaction in both an OLS regression to predict colonoscopy take-up $\left(\beta_{\text {forget_proxy_x_planning_prompt }}=0.013, p=0.024\right)$ and a Cox proportional

\footnotetext{
${ }^{2}$ Note that because our data set was $99.6 \%$ Caucasians and Hispanics, this question was posed about Caucasians vs. Hispanics only.
} 
hazards model to predict the daily colonoscopy hazard (Hazard_Ratioforget_proxy_x_planning_prompt $=$ $1.19, p=0.034)$

It is important to note that the variables used as proxies for forgetfulness likely capture many other underlying population characteristics as well. Thus, these results should be interpreted with caution. However, it is reassuring to see that our planning prompt treatment appears to be most helpful to those who, by one crude measure, are at the highest risk of forgetting to receive a colonoscopy.

\section{Concluding Discussion}

This paper provides evidence from the field that planning prompts have the power to help people overcome forgetfulness and follow through on their plans even when that follow-through is in the distant future, requires advance planning, and involves a costly, unpleasant action. The effect of the planning prompt analyzed in this study is of roughly the same magnitude as the variation associated with a $10 \%$ decrease in the (insurance-adjusted) monetary cost of receiving a colonoscopy. These findings have implications for organizations in search of methods for encouraging people to follow through on beneficial opportunities that are often put off or forgotten due to memory problems and failures of self-regulation. Further, public health interventions based on the intervention studied in this paper may be able to save many lives at much lower cost than the price mechanisms that are often suggested for promoting behavior change.

Unfortunately, our experiment does not allow us to pinpoint the precise mechanisms responsible for the effectiveness of the treatment mailing. It may be the case that our treatment mailing prompted more recipients to schedule colonoscopy appointments than our control 
mailing but had no effect on the rate at which scheduled appointments were attended. Another possibility is that appointments were scheduled at equal rates in our control and treatment conditions, but the treatment increased appointment attendance by: (a) embedding plans more firmly in memory, (b) prompting people to solve logistical challenges associated with attending appointments, and/or (c) providing a physical reminder that was more likely to be retained. Further research disentangling the precise mechanisms responsible for the effectiveness of the intervention would be valuable. By demonstrating that planning prompts are effective, we hope to spur wider use of this technique and to encourage further exploration of the causes and consequences of its effectiveness. 


\section{Tables}

Table 1. Subject characteristics for the full sample and broken down by experimental condition

\begin{tabular}{|c|c|c|c|}
\hline & $\begin{array}{l}\text { Full Sample } \\
(\mathrm{N}=11,918) \\
\end{array}$ & $\begin{array}{c}\text { Control Condition } \\
(\mathrm{N}=5,898) \\
\end{array}$ & $\begin{array}{c}\text { Treatment Condition } \\
\qquad(\mathrm{N}=6,020) \\
\end{array}$ \\
\hline Male & $51 \%$ & $50 \%$ & $51 \%$ \\
\hline Age (SDs) & $57.5(4.9)$ & $57.5(4.8)$ & $57.5(4.9)$ \\
\hline Has 1+ Children & $9.9 \%$ & $9.6 \%$ & $10.1 \%$ \\
\hline Caucasian & $95.0 \%$ & $94.9 \%$ & $95.1 \%$ \\
\hline Black & $0.1 \%$ & $0.1 \%$ & $0.1 \%$ \\
\hline Hispanic & $4.7 \%$ & $4.8 \%$ & $4.5 \%$ \\
\hline Asian & $0.3 \%$ & $0.3 \%$ & $0.2 \%$ \\
\hline First Reminder & $76.8 \%$ & $77.1 \%$ & $76.5 \%$ \\
\hline Colonos copy \% Coverage (SD) & $87.2 \%(8.9 \%)$ & $87.3 \%(9.0 \%)$ & $87.1 \%(8.9 \%)$ \\
\hline Employer 1 (June Mailing) & $15.5 \%$ & $16.1 \%^{\dagger}$ & $14.9 \%$ \\
\hline Employer 2 (July Mailing) & $1.3 \%$ & $1.4 \%$ & $1.2 \%$ \\
\hline Employer 3 (August Mailing) & $60.0 \%$ & $59.5 \%$ & $60.4 \%$ \\
\hline Employer 4 (August Mailing) & $23.2 \%$ & $23.0 \%$ & $23.5 \%$ \\
\hline
\end{tabular}

${ }^{\dagger} p<0.10$ in a two sample t-test (for continuous variables) or z-test (for dichotomous variablse) comparing means of a given demographic characteristic in the control and treatment conditions 
Table 2. This table presents beta coefficients from an OLS regression (Model 1) and hazard ratios from a Cox hazard regression (Model 2) predicting the responsiveness of study participants to colonoscopy reminder mailings as a function of experimental condition and observable characteristics of the participant. Standard errors are in parentheses.

\begin{tabular}{|c|c|c|}
\hline & Model 1 & Model 2 \\
\hline Type of Regression Model: & OLS & Cox \\
\hline & Colonoscopy & Days between \\
\hline Dependent Variable: & Received before & Mailing and \\
\hline & March 2011 & Colonoscopy Receipt \\
\hline \multirow[t]{2}{*}{ Treatment Condition } & $0.010^{*}$ & $1.159^{*}$ \\
\hline & $(0.005)$ & $(0.082)$ \\
\hline \multirow[t]{2}{*}{ Age } & -0.001 & 0.992 \\
\hline & $(0.000)$ & $(0.008)$ \\
\hline \multirow[t]{2}{*}{ Female } & -0.006 & 0.912 \\
\hline & $(0.005)$ & $(0.065)$ \\
\hline \multirow[t]{2}{*}{ Caucasian } & $0.023^{*}$ & $1.447 \dagger$ \\
\hline & $(0.011)$ & $(0.274)$ \\
\hline \multirow[t]{2}{*}{ Has 1+ Children } & 0.011 & 1.145 \\
\hline & $(0.009)$ & $(0.138)$ \\
\hline \multirow[t]{2}{*}{ Colonoscopy \% Coverage } & $0.088^{* *}$ & $3.767 * *$ \\
\hline & $(0.034)$ & $(1.926)$ \\
\hline \multirow[t]{2}{*}{ First Reminder } & -0.002 & 0.953 \\
\hline & $(0.019)$ & $(0.276)$ \\
\hline \multirow[t]{2}{*}{ Employer 1 Indicator } & -0.012 & 0.841 \\
\hline & $(0.021)$ & $(0.262)$ \\
\hline \multirow[t]{2}{*}{ Employer 2 Indicator } & 0.034 & 1.405 \\
\hline & $(0.028)$ & $(0.528)$ \\
\hline \multirow[t]{2}{*}{ Employer 3 Indicator } & -0.008 & 0.883 \\
\hline & $(0.019)$ & $(0.257)$ \\
\hline Observations & 11,918 & 11,918 \\
\hline $\mathbf{R}^{2}$ or Log Pseudolike lihood & 0.002 & -7436.30 \\
\hline
\end{tabular}




\section{Figures}

Figure 1. Sticky note "nudge."

\section{Don't forget!}

\section{Colonoscopy appointment}

with

on

Figure 2. Experimentally varied reminder mailers sent to study participants.

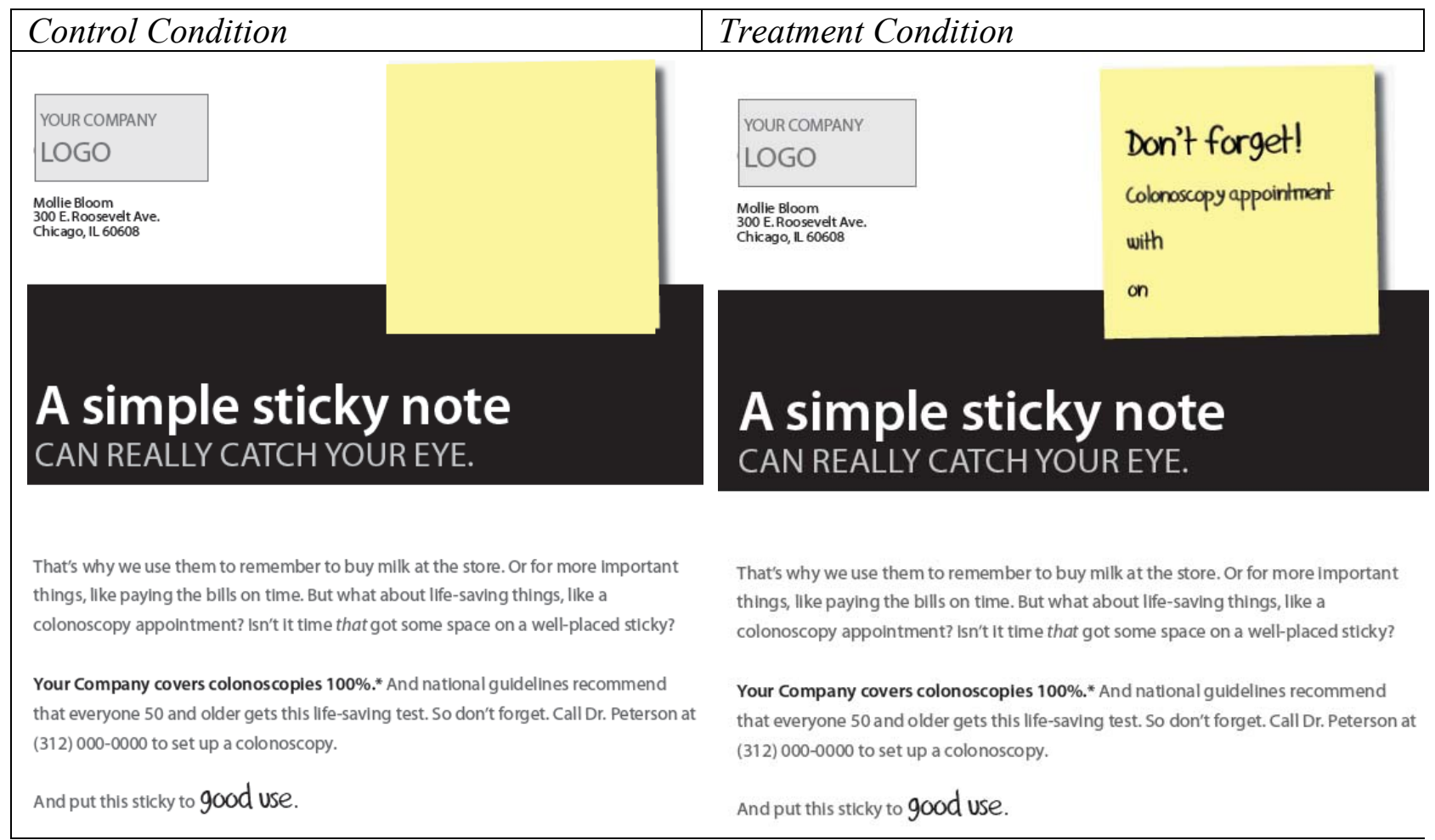


Figure 3. Colonoscopy rates by experimental condition.

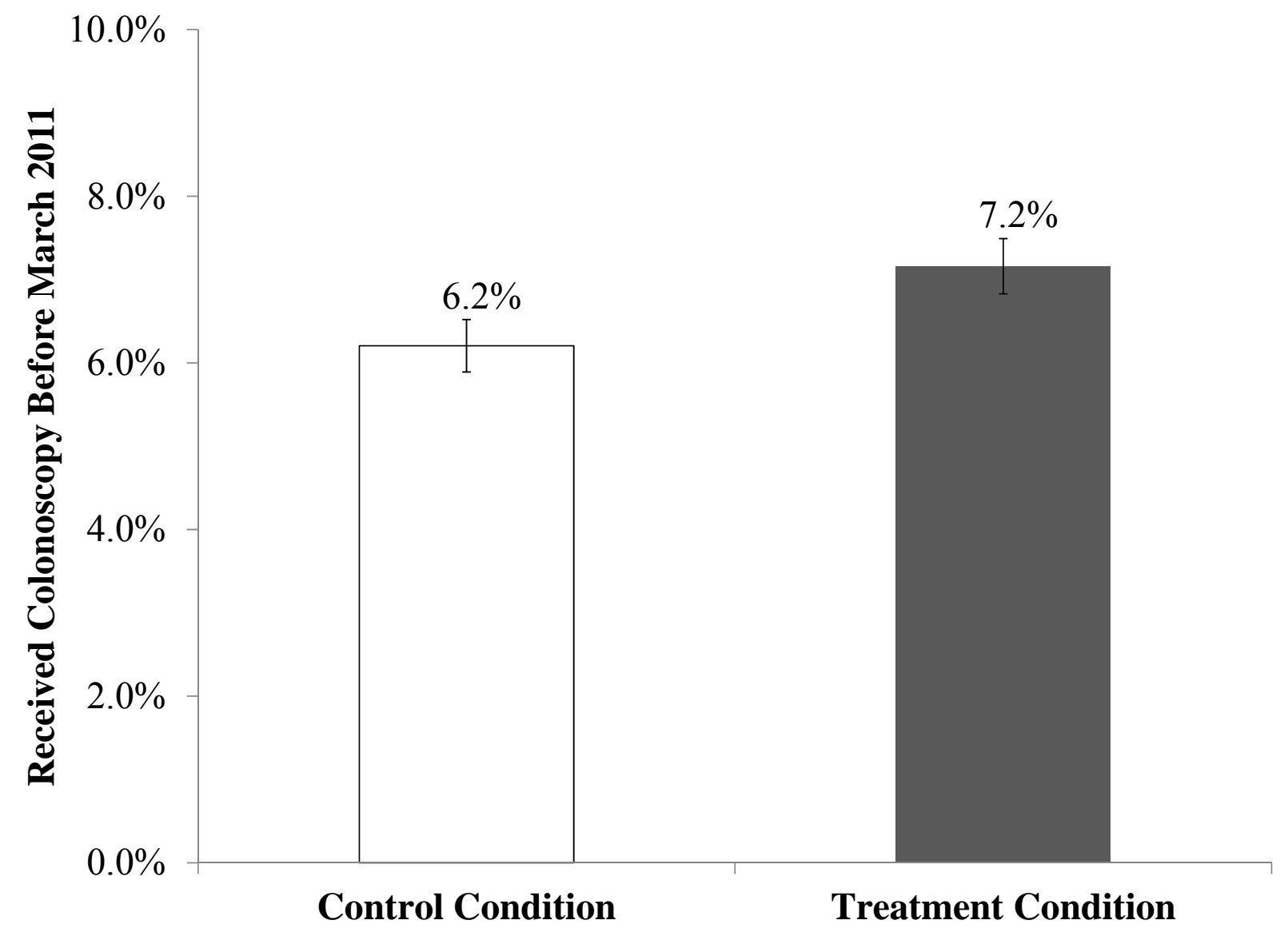


Figure 4. Estimated planning prompt (PP) treatment effects (using our primary regression specification) on colonoscopy take-up as a function of demographic variables classified by survey respondents as predictive of forgetfulness about medical tests. For continuous variables (age and coverage), treatment effects are estimated for the variables' $25^{\text {th }}$ and $75^{\text {th }}$ percentiles.

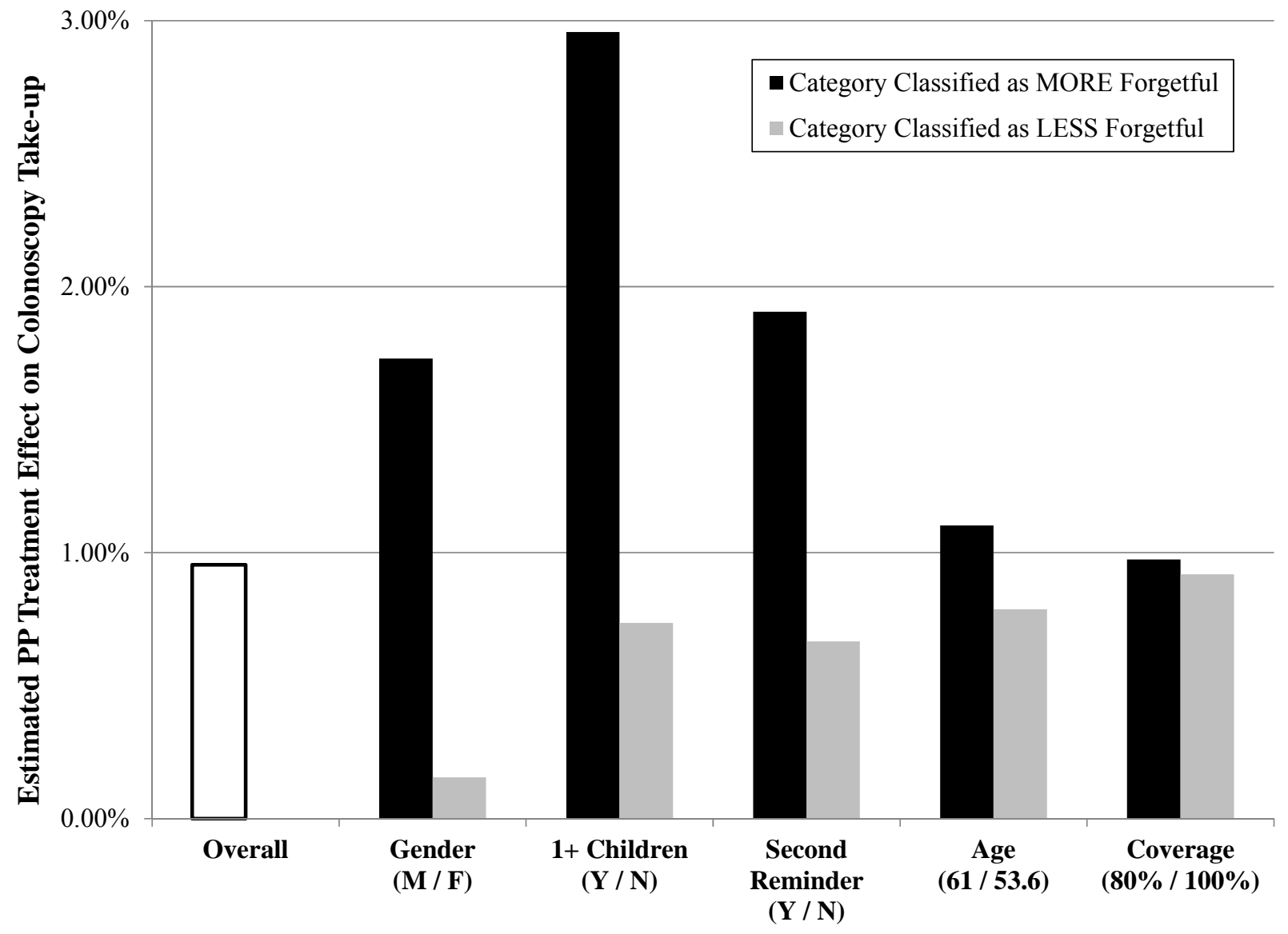




\section{Bibliography}

Armitage, C. J. \& Conner, M. (2001). Efficacy of the theory of planned behavior. British Journal of Social Psychology, 40(4), 471-499.

Bamberg, S. (2000). The promotion of new behavior by forming an implementation intention: results of a field experiment in the domain of travel mode choice. Journal of Applied Social Psychology, 30(9), 1903-1922.

Bamberg, S. (2002). Implementation intention versus monetary incentive: comparing the effects of interventions to promote the purchase of organically produced food. Journal of Economics Psychology, 23, 573-587.

Dholakia, U.M. \& Bagozzi, R.P. (2003). As time goes by: how goal and implementation intentions influence enactment of short-fuse behavior. Journal of Applied Social Psychology, 33, 889-922.

Ebbinhaus, H. (1885). Uber das Gedachtnis [Memory]. Leipzig, Germany: Duncker and Humblot.

Gollwitzer, P. M. (1999). Implementation intentions: strong effects of simple plans. American Psychologist, 54(7), 493-503

Gollwitzer, P. M. \& Sheeran, P. (2006) Implementation intentions and goal achievement: a metaanalysis of effects and processes. Advances in Experimental Social Psychology, 38, 69-119.

Koestnet, R., Lekes, N., Powers, T. A., Chicoine, E. (2002). Attaining personal goals: selfconcordance plus implementation intentions equals success. Journal of Personality and Social Psychology, 83(1), 231-244.

Lawton, R., Conner, M., \& Prestwich, A. (2003). The use of implementation intentions and the decision balance sheet in promoting exercise behavior. Psychology and Health, 18(6), 707-721.

Levanthal, H., Singer, R., \& Jones, S. (1965). Effects of fear and specificity of recommendation upon attitudes and behavior. Journal of Personality and Social Psychology, 2(1), 20-29.

Leventhal, H., Watts, J. C., \& Pagano, F. (1967). Effects of fear and instructions on how to cope with danger. Journal of Personality and Social Psychology, 6(3), 313-321.

Milkman, K. L., Beshears, J., Choi, J. J., Laibson, D., \& Madrian, B. C. (2011). Using implementation intentions prompts to enhance influenza vaccination rates. Proceedings of the National Academy of Sciences, 108(26), 10415-10420.

Milkman, K.L., Rogers, T. \& Bazerman, M.H. (2008). Harnessing our inner angels and demons: 
What we have learned about want/should conflicts and how that knowledge can help us reduce short-sighted decision making. Perspectives on Psychological Science, 3(4), 324-338.

Nickerson, D.W \& Rogers, T. (2010). Do you have a voting plan?: implementation intentions, voter turnout, and organic plan making. Psychological Science, 21(2), 194-199.

O’Donoghue, M. \& Rabin, M. (1999). Doing it now or later. American Economic Review, 89, 103-124.

Orbell, S., Hodgkins, S., \& Sheeran, P. (1997). Implementation intentions and the theory of planned behavior. Personality \& Social Psychology Bulletin, 23(9), 945-954

Rutter, D. R., Steadman, L., \& Quine, L. (2006). An implementation intentions intervention to increase uptake of mammography. Annals of Behavioral Medicine, 32(2), 127-134.

Schacter, D.L. (1999). The Seven Sins of Memory: Insights from Psychology and Cognitive Neuroscience. American Psychologist, 54(3), 182-203.

Sheeran, P., \& Orbell, S. (1999). Augmenting the theory of planned behavior: roles for anticipated regret and descriptive norms. Journal of Applied Social Psychology. 29(10), 21072142.

Sheeran, P., \& Orbell, S. (2000). Using implementation interventions to increase attendance for cervical cancer screening. Health Psychology, 19(3), 283-289.

Sniehotta F.F., Scholz, U., \& Schwarzer, R. (2006). Action plans and coping plans for physical exercise: A longitudinal study in cardiac rehabilitation. British Journal of Health Psychology, 11, 23-37.

Thaler, R. H. \& Sunstein, C. R. (2008). Nudge: Improving Decision About Health, Wealth, and Happiness. Connecticut: Yale University Press.

U.S. Preventive Services Task Force (2008). Screening for Colorectal Cancer: U.S. Preventive Services Task Force Recommendation Statement. External Web Site Icon AHRQ Publication 0805124-EF-3, October 2008. Agency for Healthcare Research and Quality, Rockville, MD.

Verplanken, B. \& Faes, S. (1999). Good intentions, bad habits, and effects of forming implementation intentions on healthy eating. European Journal of Social Psychology, 29, 591604

Wagner, A. D., Schacter, D. L., Rotte, M., Koutstaal, W., Maril, A., Dale, A. M., et al. (1998). Building memories: remembering and forgetting of verbal experiences as predicted by brain activity. Science, 281, 1188-1191. 
Webb, T. L. \& Sheeran, P. (2007). How do implementation inentions promote goal attainment? A test of component processes. Journal of Experimental Social Psychology, 43, 295-302.

Zauber, A. G., Lansdorp-Vogelaar, I., Knudsen, A. B., Wilschut, J., van Ballegooijen, M., \& Kuntz, K. M. (2008) Evaluating test strategies for colorectal cancer screening: a decision analysis for the U.S. Preventive Services Task Force. Annals of Internal Medicine, 149, 659-69.

Zauber, A. G., Winawer, S. J., O'Brien, M. J., Lansdorp-Vogelaar, I., van Ballegooijen, M., Hankey, B. F., Shi, W., Bond, J. H., Schapiro, M. Panish, J. F., Stewart, E. T., \& Waye, J. D. (2012). Colonoscopic polypectomy and long-term prevention of colorectal-cancer deaths. The New England Journal of Medicine, 366, 687-696 
Appendix

Survey Question about Forgetfulness Posed to Workers on Amazon's Mechanical Turk

Consider a population of U.S. adults age $45-75$ who are due to receive a specific medical test. All of these adults have $70 \%-100 \%$ insurance coverage for the test and receive a reminder to receive the test in the mail.

For each of the groups listed below, please guess who would be at higher risk of forgetting to get the test due to an over-taxed memory and/or general struggles with forgetfulness.

Please use the scales below as follows...

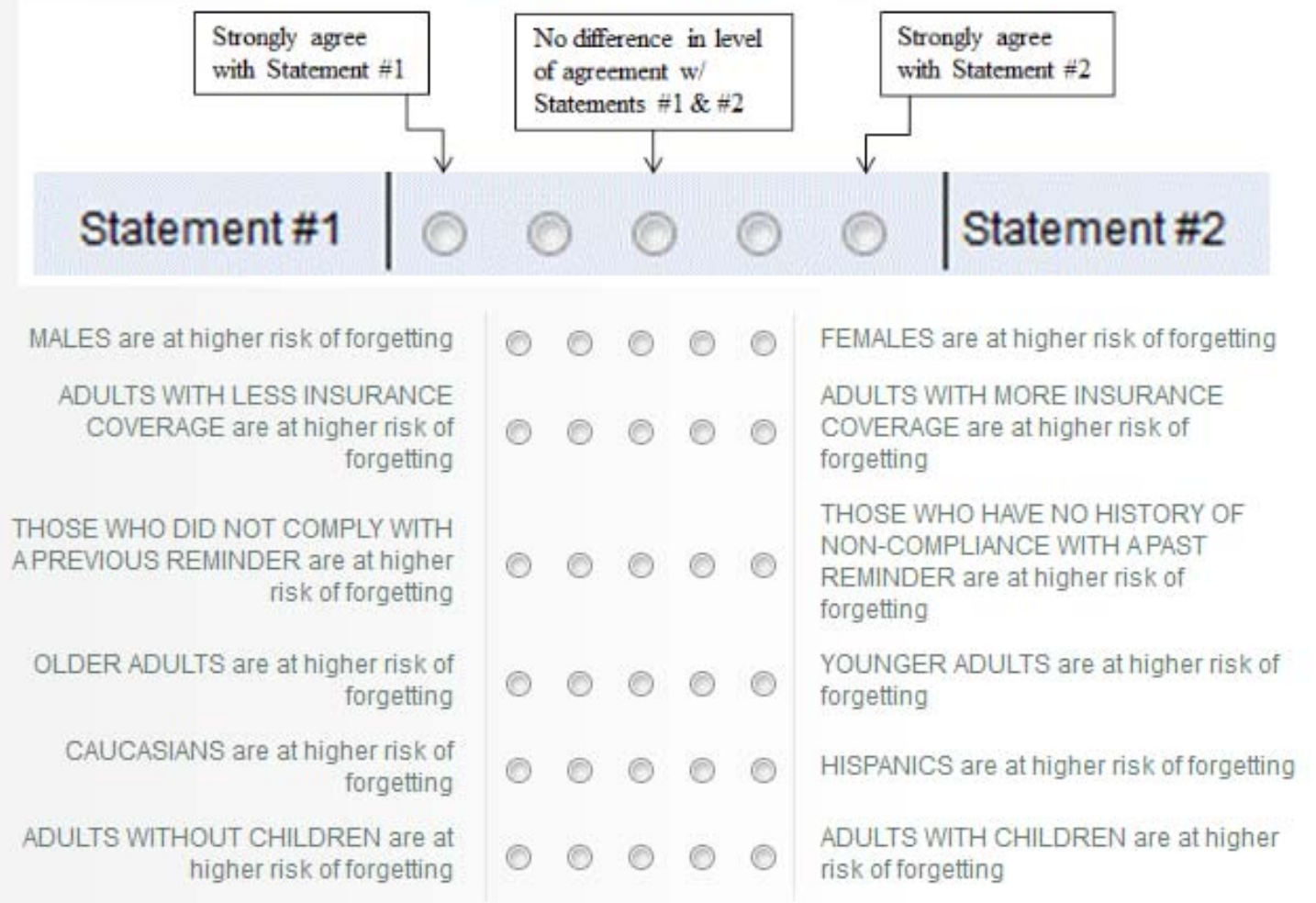

Note that the order of statements was randomized across survey respondents. 